\title{
A COMBINED METHOD TO PREDICT IMPACT PRESSURE ON PLANING CRAFT
}

\author{
Hossein Tahmasvand \\ Amirkabir University of Technology, Iran \\ Hamid Zeraatgar ${ }^{*}$ \\ Amirkabir University of Technology, Iran \\ *Corresponding author: hamidz@aut.ac.ir (H. Zeraatgar)
}

\begin{abstract}
Prediction of the pressure distribution on a planing craft in waves deeply affects its structural design and safe operation. In this paper, the possibility of pressure prediction for the planing craft in waves is studied. A combined method is formulated by which craft motions in waves are computed using a 2.5D method, and the impact pressure is anticipated by the equivalent wedge method. Experiments are conducted to record the vertical acceleration and pressure time trends on a model. Comparing the results of the combined method with the experiments indicates that this approach successfully predicts the heave and pitch motions and the time evolution of the acceleration and pressure. The method presents good estimations for the peaks of the acceleration and pressure. Using the combined method, a parametric study on maximum peak acceleration and pressure is also conducted for various forward velocities and wave heights. It has been shown that the combined method is a fast and reliable tool for maximum peak pressure prediction. The method may be employed for structural design and optimization.
\end{abstract}

Keywords: impact pressure; acceleration; 2.5D method; equivalent wedge method; planing craft.

\section{INTRODUCTION}

Accurate prediction of the pressure distribution on a planing craft plays a major role in the design of a safe structure. Both instantaneous impact pressure and mean force are important for a structure exposed to the impact of water. A very sharp peak of short duration is the most important feature of the impact pressure and acceleration. The impact totally disappears in heave and pitch motions. Therefore, when a method correctly predicts the motions, it does not guarantee that the pressure distribution, especially the peak pressure, has been evaluated properly.

Various methods such as experimental, semi-empirical, numerical and computational fluid dynamics (CFD) methods have been employed to analyse the dynamics of planing craft in waves. Fridsma [1] experimentally examined the motions of different prismatic planing models in regular waves. Savitsky et al. [2] presented relations for added resistance, vertical acceleration, and buoyancy force in the wave, using the results of Fridsma [1]. Martin [3] introduced a linear model for the dynamics of planing craft in the frequency domain. The linear model presented by Martin was the first model utilised for the dynamics of planing craft. Zarnick [4], based on Martin's model, developed a nonlinear mathematical model for the planar motion of planing craft in the time domain. Many researchers, including Hicks et al. [5], Akers [6], Van Deyzen [7], Sayeed [8], Ruscelli [9], and Pennino [10], have attempted to improve the Zarnick model. 
Based on the reviewed literature, the $2.5 \mathrm{D}$ method (developed by Zarnick [4]) is a fast and reliable means for the prediction of the heave and pitch motions and the vertical acceleration of planing craft in waves [7]. The 2.5D method computes the motion in waves based on momentum changes and does not provide an estimation of the pressure. As far as the pressure distribution on the planing craft is concerned, Von Karman [11] and Wagner [12] presented an analytical method based on potential theory for the two-dimensional (2D) wedge in water entry. Many researchers developed Wagner's method further $[13,14]$. They only estimated the pressure on 2D wedges in water entry, and few studies have addressed the pressure distribution on a planing craft in waves. Smiley $[15,16]$ recorded the pressure distribution on $\mathrm{V}$-shaped planing craft having a range of dead-rise angles at several trim angles in calm water. Gray et al. [17], according to the results of Smiley, developed a regression formula for threedimensional pressure distribution on a V-shaped prismatic planing craft. Rosen and Garme [18] experimentally measured the bottom pressure on a high-speed craft in waves. Rosen [19] presented an interpolation method for calculating the pressure distribution in waves. Camilleri et al. [20] conducted full-scale trials on a high-speed craft in waves and studied the pressure, accelerations, and strain time trends.

Despite providing valuable insights into the pressure distribution on planing craft by the experimental and numerical methods, the analytical/regression approach is more attractive to engineers for structural design and optimisation. Several regression formulae based on experimental, analytical, and numerical methods were introduced to estimate the impact pressure on planing craft. They are extensively applied for structural design in the rules of classification societies [21]. Allen et al. [22] presented a regression method to calculate the impact pressure for structural design. Razola et al. [21] re-formulated and evaluated the impact pressure using the Allen method [22]. They combined the 2.5D method and a pressure shape function modelling technique. Ghadimi et al. [23] presented a mathematical model based on $2 \mathrm{D}+\mathrm{t}$ theory for predicting the pressure distribution of a hard-chine planing craft in planing and semi-planing modes. Ghasemi et al. [24] developed a mathematical model based on the Savitsky model to study the performance of stepped planing hulls. Jones and Allen [25] proposed the "equivalent wedge method" to estimate the pressure distribution for given motion in waves. The equivalent wedge method includes the three-dimensional flow effect. It seems that the equivalent wedge method is more realistic than the shape function technique. The above review indicates that few analytical/regression methods of pressure estimation on planing hulls are available, while it is crucial for structural design. The available methods are also under development to better comply with the real sea environment.

Following Razola et al.'s [21] approach, this study introduces pressure calculation on planing craft in waves by combining the $2.5 \mathrm{D}$ method and the equivalent wedge method. The $2.5 \mathrm{D}$ method is a reliable method for motion and acceleration prediction. One should note that a good estimation of acceleration by the $2.5 \mathrm{D}$ method does not necessarily mean a good estimation of the pressure distribution on the structure. On the other hand, the equivalent wedge method is a robust method to estimate the pressure distribution, if motion as input is appropriately calculated. That is why a combination of the $2.5 \mathrm{D}$ method and the equivalent wedge method is employed.

In this study, a computer code is initially developed based on the $2.5 \mathrm{D}$ method. Then, the $2.5 \mathrm{D}$ method is combined with the equivalent wedge method to calculate the pressure distribution on any points on the craft. Furthermore, a model test is conducted to record accelerations and pressure for validation of the combined method results. Finally, using the combined method, a parametric study is carried out on the maximum peak acceleration and the maximum peak pressure of a planing craft.

\section{THE COMBINED METHOD FOR CALCULATING THE IMPACT PRESSURE}

In this section, a draft of the $2.5 \mathrm{D}$ method is first presented. Then, the equivalent wedge method, proposed by Jones and Allen [25], is reviewed. Finally, these two methods are combined.

\section{REVIEW OF THE 2.5D METHOD}

Having considered practical planing craft lengths and the sea wavelengths, it is assumed that the wavelengths are generally larger than the craft length and the wave slopes are small. Additionally, craft are V-shaped, hard chine with constant forward speed encountering regular head waves.

Fig. 1 shows a schematic of a planing craft in the wave. Two coordinate systems are considered; an earth-fixed coordinate system $(\mathrm{x}, \mathrm{z})$ that represents craft forward ( $\mathrm{x}$-axis) and downward (z-axis) motions, and a body-fixed coordinate system $(\xi, \zeta)$ where $\xi$ is parallel to the keel-line, and $\zeta$ is perpendicular to it. Thrust force $(\mathrm{T})$, normal force $(N)$, drag force $(D)$ and weight of craft $(\mathrm{W})$ are the main forces exerted on the craft. The normal force is the sum of the hydrodynamic and buoyancy forces.

By the use of Newton's second law in the earth-fixed coordinate system, the following equations of motions are obtained for two degrees of freedom pitch $(\theta)$ and heave $\left(z_{C G}\right)$ :

$$
\begin{gathered}
M \ddot{z}_{C G}=T_{z}-N \cos \theta+D \sin \theta+W \\
I \ddot{\theta}=N x_{c}-D x_{d}+T x_{p}
\end{gathered}
$$

where $M$ and $I$ are the craft mass and moment of inertia, respectively. $x_{c}, x_{d}$ and $x_{p}$ are the vertical distances of the forces $N, D$ and $\mathrm{T}$ from the centre of gravity, respectively. 


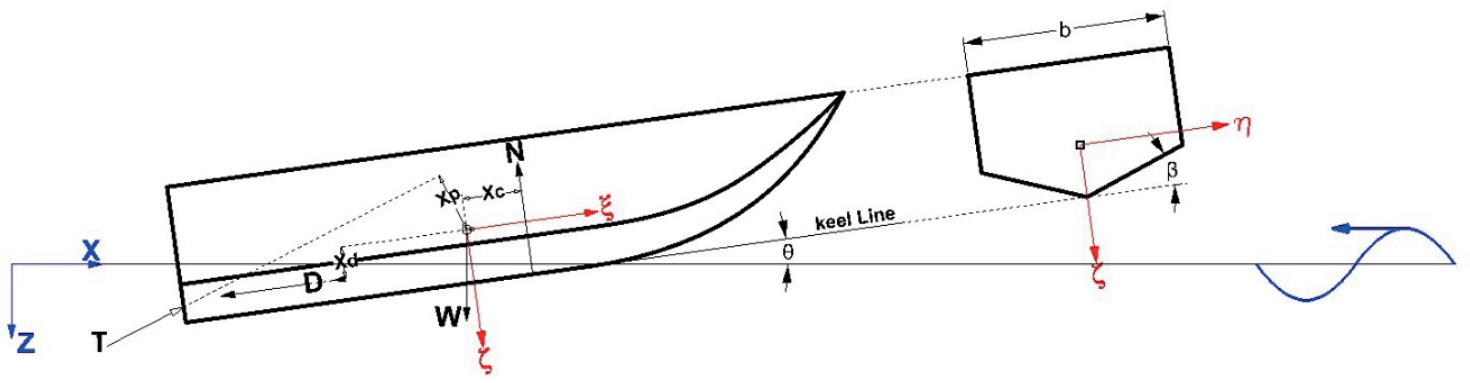

Fig. 1. Definition of coordinate systems and forces on a craft

According to the 2.5D method, the planing craft forces in waves are the sum of a series of two-dimensional forces on its 2D wedge sections. The hydrodynamic force perpendicular to the unit length of each $2 \mathrm{D}$ section, $f$, is calculated from the following equation [4]:

$$
f=-\left\{\frac{D}{D t}\left(m_{a} V\right)+C_{D . C} \rho b V^{2}\right\}
$$

where $m_{a}, C_{D, C}, b$ and $V$ are the added mass coefficient, cross-flow drag coefficient, beam and vertical velocity of each section, respectively. The cross-flow drag coefficient is $C_{D, C}=\cos \beta$ for wedge sections [26], where $\beta$ is the deadrise angle. The buoyancy force of a $2 \mathrm{D}$ wedge section is a coefficient of the submerged volume relative to the static water level surface as $f_{B}=-a \rho g A$, where $a$ is the buoyancy force coefficient ( $a=0.5[26])$, and $A$ is the submerged area of the wedge section.

The instantaneous hydro-mechanic forces exerted on the wetted length $(l)$ of the craft are an integration of the instantaneous forces on the $2 \mathrm{D}$ sections along the wetted length:

$$
F_{z}(t)=\int_{l} f \cos \theta d \xi+\int_{l} f_{B} d \xi
$$

The hydro-mechanic moment about CG is also calculated by integrating the product of the normal force per unit length and the corresponding moment arm along the wetted length:

$$
F_{\theta}(t)=\int_{l} f(\xi, t) \xi d \xi+\int_{l} f_{B} \xi d \xi
$$

By assuming $x_{c}=0$ and ignoring $D \sin \theta$, g due to relatively small $\theta$, two coupled non-linear differential equations are concluded:

$$
\begin{gathered}
\left(M+M_{a} \cos ^{2} \theta\right) \ddot{z}_{C G}-\left(Q_{a} \cos \theta\right) \ddot{\theta}=F_{z}^{\prime}+W \\
\left(-Q_{a} \cos \theta\right) \ddot{z}_{C G}+\left(I+I_{a}\right) \ddot{\theta}=F_{\theta}^{\prime}
\end{gathered}
$$

where $M_{a}, Q_{a}$, and $I_{a}$ are the added mass of the craft, pitchinduced added mass to heave, and pitch-added moment of inertia, respectively. Finally $F_{z}^{\prime}$, and $F_{\theta}^{\prime}$ are calculated as follows:

$$
F_{z}^{\prime}=F_{z}-\left(\left(M_{a} \cos ^{2} \theta\right) \ddot{z}_{C G}-\left(Q_{a} \cos \theta\right) \ddot{\theta}\right)
$$

$$
F_{\theta}^{\prime}=F_{\theta}-\left(\left(-Q_{a} \cos \theta\right) \ddot{z}_{C G}+I_{a} \ddot{\theta}\right)
$$

Equations (8) and (9) are solved by using the Runge-Kutta integration.

\section{REVIEW OF THE EQUIVALENT WEDGE METHOD}

In the equivalent wedge method, a $3 \mathrm{D}$ planing hull is divided into a set of incremental wedge portions. It is assumed that each portion is a part of an equivalent prismatic wedge, which has the same width, dead-rise angle, and trim. The parameters such as submerged depth and dead-rise angle are determined in the middle section of the portion. The centreline pressure distribution of the prismatic wedge is calculated using the trim, dead-rise angle, beam, and wetted length. The pressure distribution on the centreline of the portion is a portion of the pressure distribution of the prismatic wedge, as seen in Fig. 2. The transverse pressure distribution is computed using the centreline pressure.

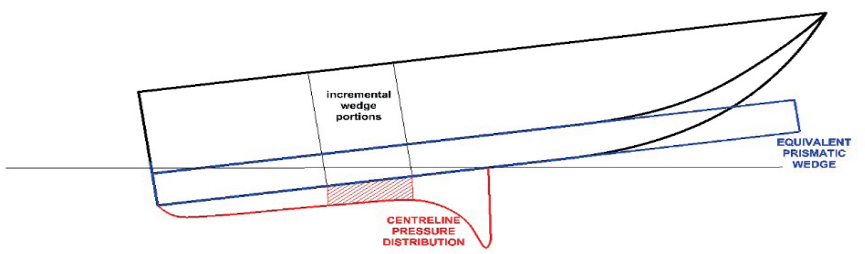

Fig. 2. Pressure distribution on the centreline of an equivalent wedge

The prismatic wedge is composed of chine-wet and chinedry sections (see Fig. 3). The centreline pressure distribution of the prismatic wedge in the wet-chine sections of the prismatic wedge is estimated as follows [17]: 
$\frac{P_{c}}{\frac{1}{2} \rho V^{2}}=\left[1-\left(\frac{\mu-\cos \theta}{1-\mu \cos \theta+\sin \theta \sqrt{1-\mu^{2}}}\right)\right] \cos \beta$

where $\theta, \beta$ and $V$ are the trim angle, dead-rise angle and vertical relative velocity of the equivalent wedge, and $\mu$ is equivalent to the longitudinal coordinate of a section $(-1 \leq \mu \leq 1) \cdot \mu=-1, \mu=\cos \theta$ and $\mu=1$ represent sections of the transom, maximum pressure and fore end of the waterline of the prismatic wedge, respectively.

The centreline pressure on the dry-chine sections of the prismatic wedge is obtained by averaging the pressure distribution predicted by Eq. (10) with the centreline distribution predicted by immersing wedge theory (Eq. (12)).

The transverse pressure distribution is computed using the centreline pressure. It was presented in [17] for the section with wet-chine as follows:

$$
\frac{P}{P_{c}}=1-\left(\frac{\cos \varepsilon}{1+\sin \varepsilon}\right)^{2 n}
$$

where $n=(\pi-2 \beta) / \pi, P_{c}$ is the pressure on the keel, and $\varepsilon$ is equivalent to the transverse coordinate of a point on a section $(0 \leq \varepsilon \leq \pi / 2) . \varepsilon=\pi / 2$ and $\varepsilon=0$ represent $\eta=0$ and $\eta=C$, respectively.The transverse pressure distribution for dry-chine sections is computed as follows [17]:

$\frac{P}{1 / 2 \rho V^{2}}=\left[\frac{\pi \cot \alpha}{\sqrt{1-(\eta / w)}}-\frac{1}{(w / \eta)^{2}-1}\right] \sin ^{2} \theta$

$\alpha=\tan ^{-1}\left(\frac{\pi}{2} \sqrt{\frac{\sin ^{2} \beta+K^{2} \tan ^{2} \theta}{K^{2}-2 K \sin ^{2} \beta-K^{2} \sin ^{2} \beta \tan ^{2} \theta}}\right)$

$K \approx \frac{\pi}{2}\left(1-\frac{3 \tan ^{2} \beta \cos \beta}{1.7 \pi^{2}}-\frac{\tan \beta \sin ^{2} \beta}{3.3 \pi}\right)$

$\frac{\eta}{2 b}=k \cos \beta \int_{\varepsilon}^{\pi / 2}\left[(1+\sin \varepsilon)^{n}(\cos \varepsilon)^{1-n} \sin \varepsilon\right] d \varepsilon$

$\frac{1}{k}=4 \cos \beta \int_{0}^{\pi / 2}\left[(1+\sin \varepsilon)^{n}(\cos \varepsilon)^{1-n} \sin \varepsilon\right] d \varepsilon$

where $\rho$ and $w$ are the water density and half of the wetted width. $w$ is presented as follows:

$$
\frac{w}{c}=\frac{\lambda_{t}-\xi}{\lambda_{t}-\lambda_{w c}}, \quad \xi>\lambda_{w c}
$$

$$
\lambda_{w c}=\lambda_{t}-\frac{\tan \beta}{\pi \tan \theta}
$$

where $\lambda_{t}$ and $\lambda_{w c}$ are the total wetted length and the wetted chine region length relative to the beam, respectively (see Fig. 3).

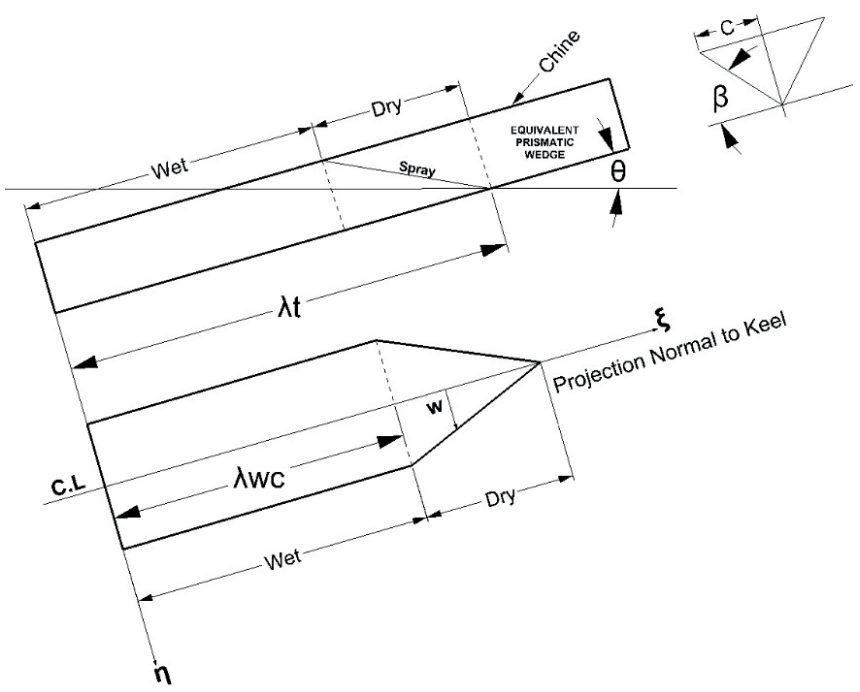

Fig. 3. Equivalent prismatic wedge

\section{THE COMBINED METHOD}

A procedure is developed to implement a combination of the 2.5D method and the equivalent wedge method for estimation of the pressure distribution on a planing hull. The procedure is shown in Fig. 4 and a summary of the procedure steps is as follows:

1) Planing craft specifications, in a certain regular wave, at given forward speed, are input data to this method.

2) The hydrodynamic forces and hydrodynamic moment are calculated as a function of time using Eqs. (8) and (9).

3) Accelerations, velocities and displacements are calculated through solving Eqs. (6) and (7) using the Runge-Kutta method,

4) Velocities and displacements are substituted into Eq. (10) and Eq. (12) to estimate the pressure distribution. 


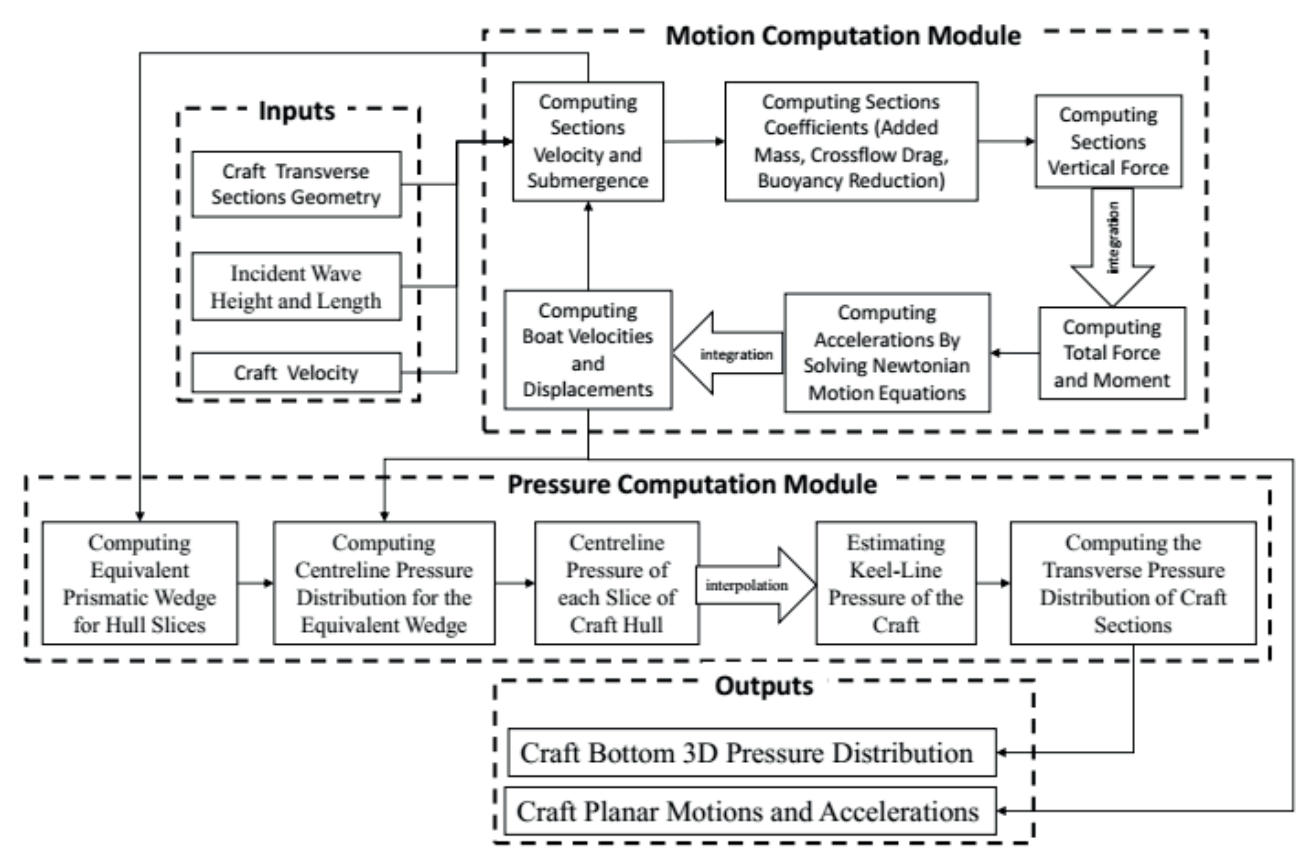

Fig. 4. Procedure of the combined method for the pressure prediction

\section{EXPERIMENTAL SET-UP}

To validate the combined method, a set of experiments on a planing craft in waves is conducted in the towing tank of the National Iranian Marine Laboratory (NIMALA) [27]. A planing hull with a hard chine $\mathrm{V}$-shape, variable dead-rise angle and length of 23 meters is chosen for the experiment [28]. A model of $1 \mathrm{~m}$ is manufactured based on the main particulars given in Table 1. Fig. 5 shows the body plan and the position of the pressure transducers. Five PCB-102B04 pressure transducers are mounted at specified places on desired sections for recording the hydrodynamic pressure, and a Triaxial mini (5 mg) high sensitivity PCB-356A32 accelerometer is mounted at the centreline of Sec. 2 for recording the vertical acceleration. Following Zeraatgar et al.'s [29] recommendation, the data are recorded at a sampling rate of $25 \mathrm{kHz}$.

Tab. 1. Main particulars of the planing hull model

\begin{tabular}{|l|c|c|}
\hline Description & Symbol & Value \\
\hline Length between perpendiculars (m) & LBP & 0.936 \\
\hline Moulded breadth at chine (m) & B & 0.197 \\
\hline Draft at aft perpendicular (m) & TA & 0.064 \\
\hline Draft at fore perpendicular (m) & TF & 0.041 \\
\hline Displacement (kg) & $\Delta$ & 6.5 \\
\hline Longitudinal centre of gravity (m) & LCG & 0.372 \\
\hline Vertical centre of gravity (m) & VCG & 0.040 \\
\hline Pitch radius of gyration $(\mathrm{m})$ & $\mathrm{K}_{\mathrm{yy}}$ & 0.291 \\
\hline
\end{tabular}

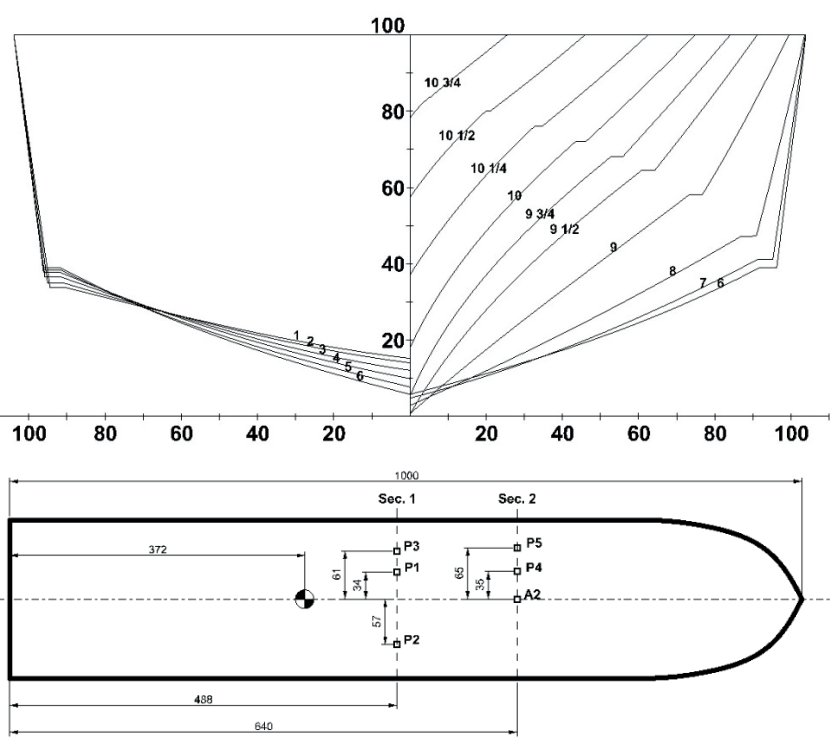

Fig. 5. Body plan of the planing hull model, and the position of pressure transducers on the model (measures are in millimeters)

\section{Experimental Procedure}

According to ITTC recommended procedures for seakeeping tests (Procedure 7.5-02-05-04), the model is towed at the intersection of the longitudinal centre of gravity and the thrust line. The model is restrained in surge, sway, roll and yaw and free to pitch and heave (Fig. 6). To adjust the towing direction, first tests are performed in calm water at a speed of $6 \mathrm{~m} / \mathrm{s}$ to record the rise-up and trim of the model. These are measured as $3.6 \mathrm{~cm}$ for rise-up and 3.0 degrees for the trim angle.

Tests are conducted in regular waves having a height of $3.5 \mathrm{~cm}$ and wavelength of $300 \mathrm{~cm}$ at a speed of $6 \mathrm{~m} / \mathrm{s}$. The model under testing is shown in Fig. 7. The pressure and acceleration are recoded in analogue form and transferred 
to the signal conditioner to be amplified. The amplifier has three gain factors: 1, 10 and 100. Knowing the approximate pressure in advance, the gain factor of the signal conditioner is appropriately selected. This kind of amplification prevents measurement of low pressure using a pressure transducer with a large measurement range, which may induce large error. The measured pressure is filtered employing the moving average with caution so that no physical peaks are lost.

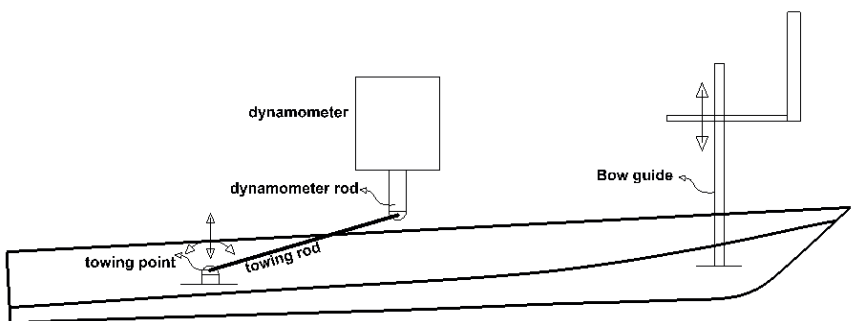

Fig. 6. Towing mechanism

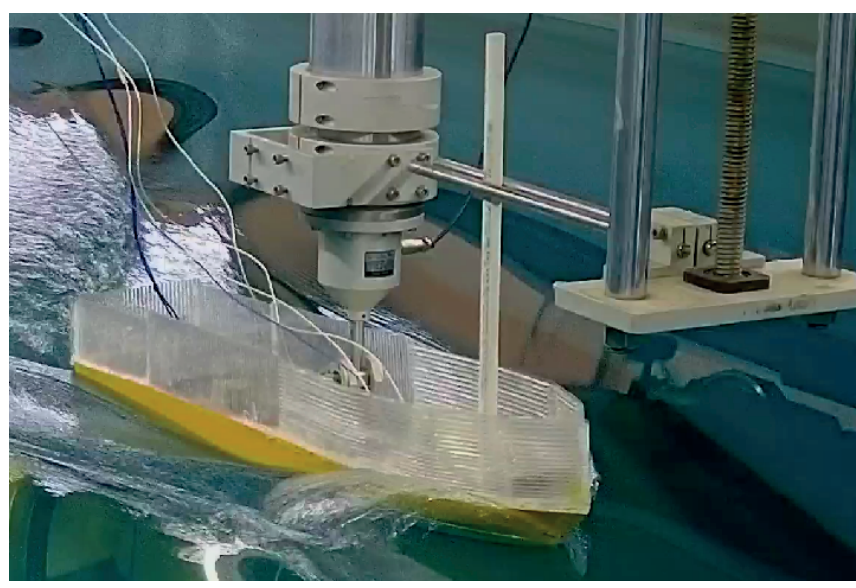

Fig. 7. Model under testing in NIMALA towing tank

\section{RESULTS AND DISCUSSION}

\section{VALIDATION OF THE COMBINED METHOD}

The model attitude in the calm water recorded in the experiment is compared with the results of the combined method in Table 2 . The combined method broadly complies with the experiment.

Table 2. Rise-up and trim of the model, the combined method in comparison with experiment

\begin{tabular}{|l|c|c|}
\hline Title & Rise-up $(\mathrm{cm})$ & Trim (degree) \\
\hline Experiment & 3.6 & 3.0 \\
\hline Combined method & 3.3 & 2.8 \\
\hline Difference (\%) & -8.3 & -6.6 \\
\hline
\end{tabular}

Due to the failure of the potentiometer in the experiment for heave and pitch measurement, the combined method results are compared with the available data, Fridsma's [1] test results in regular waves. Fridsma's A-model, presented in Table 3, is considered for the heave and pitch evaluation of the combined method. In Fig. 8, the heave and pitch of the combined method are compared with Fridsma's results, where $C_{\lambda}$ is the wavelength coefficient defined as $C_{\lambda}=(L / \lambda)$ $\left[C_{\Delta} /(L / b)^{2}\right]^{1 / 3}, C_{\Delta}$ is the load coefficient defined as $\Delta /\left(\rho g b^{3}\right)$, and $\Delta, b, L$ and $\lambda$ are the displacement, beam, hull length and wavelength, respectively. As can be seen, the results of the combined method are in good agreement with Fridsma's experiment.

Tab. 3. Characteristics of Model A of Fridsma [1]

\begin{tabular}{|c|c|c|c|c|c|c|}
\hline $\mathrm{L}(\mathrm{m})$ & $\mathrm{L} / \mathrm{b}$ & $\beta(\mathrm{deg})$ & $C_{\Delta}$ & $\mathrm{LCG}$ & $\mathrm{K}_{\mathrm{yy}}$ & $V / \sqrt{L}$ \\
\hline 1.143 & 5 & 20 & 0.608 & $0.41 \mathrm{~L}$ & $0.25 \mathrm{~L}$ & 6 \\
\hline
\end{tabular}

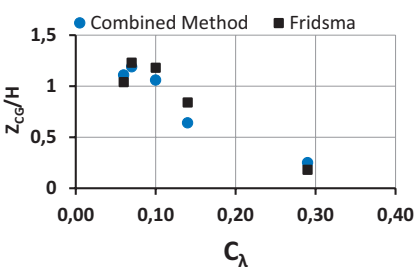

(a)

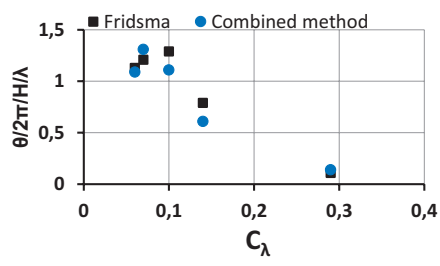

(b)
Fig. 8. A comparison of the predicted dimensionless a) heave and b) pitch motions with the experimental data reported by Fridsma [1]

A detailed insight into the validation of the combined method is achieved by comparing the acceleration and pressure with the experiment. A comparison of the vertical acceleration between the combined method and the experiment is shown in Fig. 9. The acceleration trend is almost repeating in each encounter period, which is about 0.37 seconds. In Table 4, an average of 30 acceleration peaks is presented for the combined method and the experiment. The relative differences are $-3.6 \%$ and $+0.44 \%$ for the negative and positive peak accelerations, and $9.4 \%$ for the average positive peak duration. The low relative differences show that the method accurately anticipates the peaks of accelerations. Therefore, the combined method is regarded as a reliable method for predicting the impact acceleration.

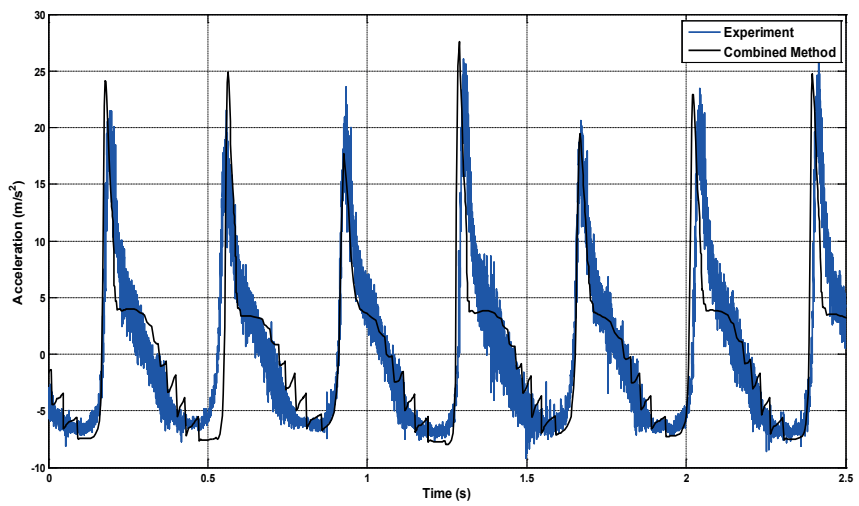

Fig. 9. A comparison between predicted and recorded acceleration at Sec. 2 $(\mathrm{V}=6 \mathrm{~m} / \mathrm{s}, \mathrm{H}=3.5 \mathrm{~cm}, \mathrm{Lw}=300 \mathrm{~cm})$ 
Tab. 4. Average of the negative and positive peak acceleration and average of the positive peak duration

\begin{tabular}{|l|c|c|c|}
\hline Parameter & 2.5D & Experiment & Difference \% \\
\hline Ave. of negative peak acc. $\left(\mathrm{m} / \mathrm{s}^{2}\right)$ & -7.2 & -7.0 & -3.6 \\
\hline Ave. of positive peak acc. $\left(\mathrm{m} / \mathrm{s}^{2}\right)$ & 22.6 & 22.5 & 0.44 \\
\hline Ave. of positive peak duration $(\mathrm{s})$ & 0.053 & 0.048 & 9.4 \\
\hline
\end{tabular}

The major concern of this study is the prediction of pressure distribution by the combined method, especially the impact pressure. In Fig. 10 and Fig. 11, the predicted pressure at several points on Sec. 1 and Sec. 2 is compared with the experiment. The combined method results and the recorded pressure time trends are both repeating in each encounter period and have the same number of peaks. They both show a high peak pressure and a low peak pressure in each encounter period. The calculated and recorded results show almost the same instant for both peaks. Within an encounter period, between the high peak and low peak and between the low peak and the next high peak, the general trends are almost the same. Hence, it may be concluded that the time trend of the combined method follows the same trend as the experiment.

As observed in Fig. 10 and Fig. 11, the pressure in the experiment is positive during the first part of an encounter period and negative/positive for the second part. The negative pressure most likely happens as the sensor fully emerges. Although the pressure predicted by the combined method is positive during the first part of each encounter period, it returns to zero in the second part of the same period. This is because, in the combined method, it is presumed that the pressure is zero in air.
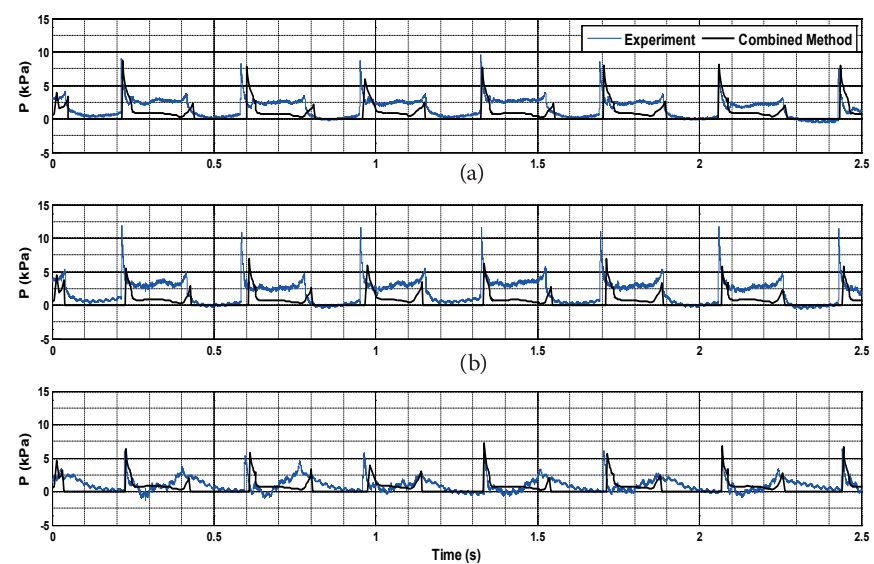

(c)

Fig. 10. Comparing predicted pressure by the combined method with the experiment at a) Point 1, b) Point $\# 2$, c) Point 3 (V=6 m/s, H=3.5 cm, $L w=300 \mathrm{~cm})$

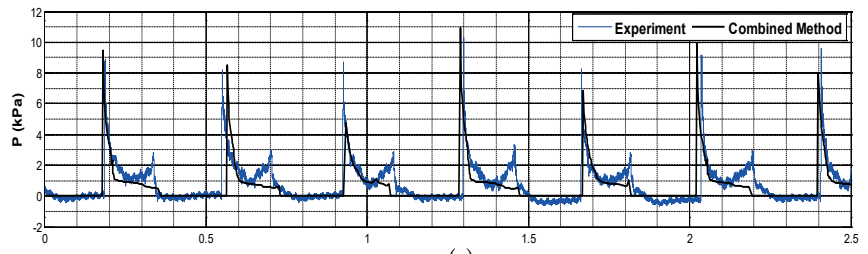

(a)

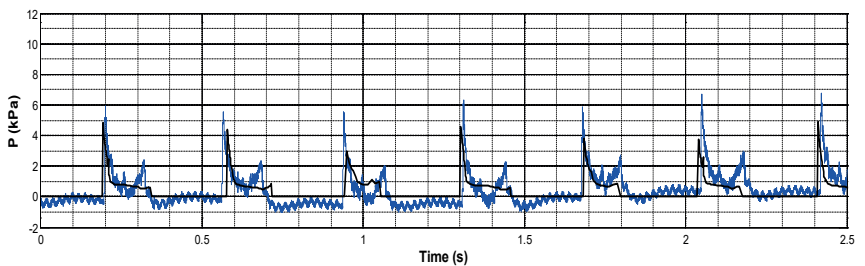

(b)

Fig. 11. Comparing predicted pressure by the combined method with the experiment at (a) Point $\#$, and (b) Point $\# 5(V=6 \mathrm{~m} / \mathrm{s}, H=3.5 \mathrm{~cm}, \mathrm{Lw}=300 \mathrm{~cm})$

In Table 5, the averages of high and low peak pressure at five locations are shown in an encounter period. It presents the results of the combined method and the experiment for average pressure and relative differences for the five considered points. The differences of the high peak ranges from $+1.3 \%$ to $-39.2 \%$, while the differences of the low peak range from $-15.1 \%$ to $-66.6 \%$. This means that the combined method tends to have a random error for the high peak, but shows a biased error for the low peak.

The combined method considerably underpredicts the high peak pressure at Sec.1, point \#2, as described above. However, for the other points, the differences are not as large as at point \#2. Despite this discrepancy, the developed code is utilised for the parametric study.

Tab. 5. The average low and high pressure peaks for the combined method and experiment

\begin{tabular}{|c|c|c|c|}
\hline \multirow{2}{*}{ Parameter } & $\begin{array}{c}\text { Combined } \\
\text { method }\end{array}$ & Experiment & Difference \% \\
\hline & \multicolumn{3}{|c|}{ Sec. 1 , point \#1 } \\
\hline Ave. High Peak $(\mathrm{kPa})$ & 9.740 & 8.716 & 11.7 \\
\hline \multirow[t]{2}{*}{ Ave. Low Peak (kPa) } & 3.143 & 3.701 & -15.1 \\
\hline & \multicolumn{3}{|c|}{ Sec. 1, point \#2 } \\
\hline Ave. High Peak (kPa) & 6.925 & 11.383 & -39.2 \\
\hline \multirow[t]{2}{*}{ Ave. Low Peak (kPa) } & 2.306 & 5.160 & -55.3 \\
\hline & \multicolumn{3}{|c|}{ Sec. 1 , point \#3 } \\
\hline Ave. High Peak (kPa) & 5.748 & 5.674 & 1.3 \\
\hline \multirow[t]{2}{*}{ Ave. Low Peak (kPa) } & 2.640 & 3.640 & -27.5 \\
\hline & \multicolumn{3}{|c|}{ Sec. 2 , point \#4 } \\
\hline Ave. High Peak (kPa) & 10.480 & 10.280 & 1.9 \\
\hline \multirow[t]{2}{*}{ Ave. Low Peak (kPa) } & 1.105 & 3.306 & -66.6 \\
\hline & \multicolumn{3}{|c|}{ Sec. 2 , point \#5 } \\
\hline Ave. High Peak (kPa) & 4.420 & 5.777 & -23.5 \\
\hline Ave. Low Peak (kPa) & 0.777 & 2.273 & -65.8 \\
\hline
\end{tabular}


Tracing of two-peak pressure in one encounter period

Recalling Fig. 10 and Fig. 11, it is observed that two peaks occur, i.e. a high peak and a low peak for an encounter period. For both the experiment and the combined method, the pressure between the high peak and the low peak is positive. However, between the low peak and the next high peak, the combined method returns to positive/zero pressure, while the experiment records positive/negative. The high peak pressure occurs as soon as the water surface passes the sensor. After the sensor is fully submerged, the pressure instantly drops. It further reduces as the chine becomes wet. Increase (decrease) of relative velocity gradually increases (decreases) the pressure. To find out the reason for the low peak, the above conditions have to be traced.

Fig. 12 shows the submergence $(\mathrm{H})$, vertical position of the chine and point \#4, time trends of calculated pressure (P) and vertical relative velocity (V) on sensor 4 . The vertical relative velocity for the point \#4 at the considered condition is always positive. This means that the combined method always has the water entry condition for this case. Let's consider the equation of relative velocity as follows:

$$
V=\dot{x}_{C G} \sin \theta-\dot{\theta} \xi+\left(\dot{z}_{C G}-w_{z}\right) \cos \theta
$$

where $\dot{x}_{C G}$ is the forward speed of the model $(6 \mathrm{~m} / \mathrm{s}$ for this case) and $w_{z}$ is the vertical velocity of the wave profile. In Eq. (19), the term $\dot{x}_{C G} \sin \theta$ is always positive and dominant in comparison with the other terms. That is why the relative velocity is always positive for the considered point. Certainly, however, this may not happen for all points on the model.

In Fig. 12, an encounter period is selected to investigate the pressure peaks. In this figure, line $t_{1}$ is the beginning of water entry of the sensor, $t_{2}$ is the instant of chine wetting, $t_{3}$ is the start of chine-wet to be chine-dry and $t_{4}$ is the instant when the sensor fully emerges from the water. The high peak occurs at an instant when the sensor is fully immersee in the water. Then, the chine becomes wet at $t_{2}$, and the pressure gradually drops due to the gradual decrease of the relative velocity. The low peak occurs between $\mathrm{t}_{3}$ and $\mathrm{t}_{4}$ when the chine becomes dry again. After $t_{4}$, the sensor fully emerges from the water and zero pressure occurs. Analysis of the physical phenomena on the pressure sensor fully supports the two peaks of pressure in one encounter period.

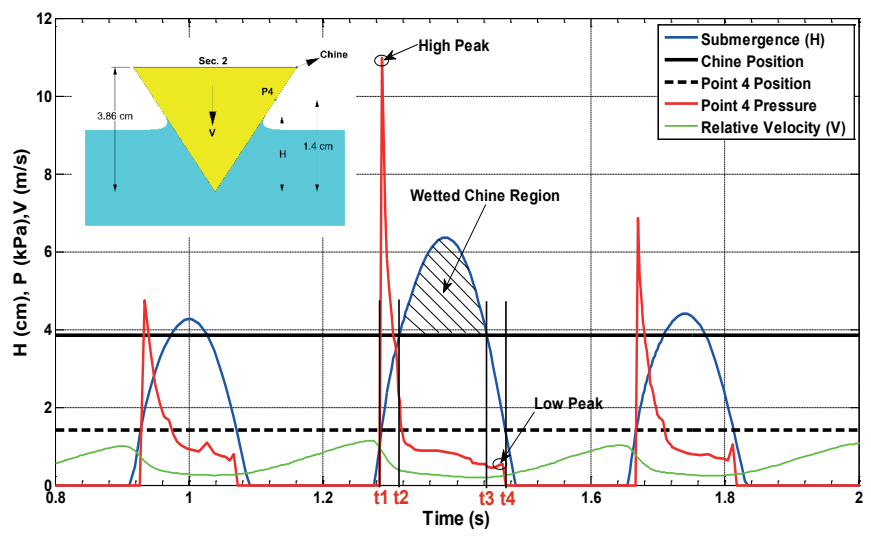

Fig. 12. Time series of submergence, predicted pressure and reletive velocity

\section{Parametric study}

The fast pressure calculation made possible by the combined method makes it a powerful tool for conducting a parametric study on the acceleration and pressure. A parametric study on the craft specified in Fig. 5 and Table 1 is performed for different forward speeds and wave heights. The considered cases and corresponding running attitudes are presented in Table 6. In addition, Fig. 13 shows the sections and points where the pressure and acceleration are calculated, respectively.

Tab. 6. The considered cases and corresponding running attitudes

\begin{tabular}{|c|c|c|c|c|}
\hline No. & H/B & $\begin{array}{c}\text { Forward speed } \\
(\mathbf{m} / \mathbf{s})\end{array}$ & $\begin{array}{c}\text { Mean trim } \\
(\mathbf{d e g})\end{array}$ & $\begin{array}{c}\text { Mean rise-up } \\
(\mathbf{c m})\end{array}$ \\
\hline $1-1$ & 0.3404 & 4.0 & 7.4 & 1.5 \\
\hline $1-2$ & 0.3404 & 4.5 & 6.2 & 1.8 \\
\hline $1-3$ & 0.3404 & 5.0 & 5.6 & 2.2 \\
\hline $1-4$ & 0.3404 & 5.5 & 4.9 & 2.4 \\
\hline $1-5$ & 0.3404 & 6.0 & 4.4 & 2.5 \\
\hline $2-1$ & 0.222 & 5.0 & 6.2 & 2.5 \\
\hline $2-2$ & 0.167 & 5.0 & 6.3 & 2.5 \\
\hline $2-3$ & 0.111 & 5.0 & 6.3 & 2.5 \\
\hline
\end{tabular}

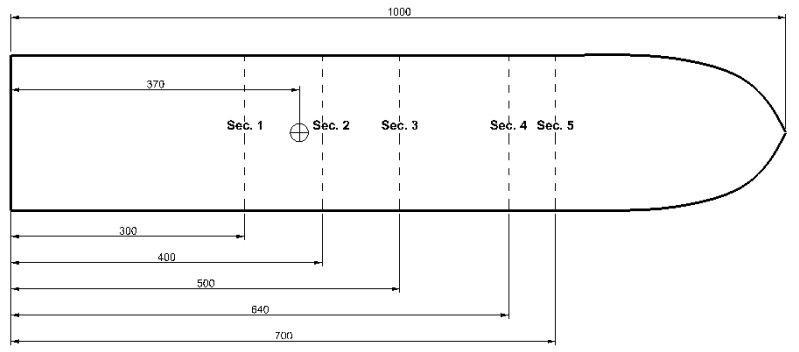

(a)

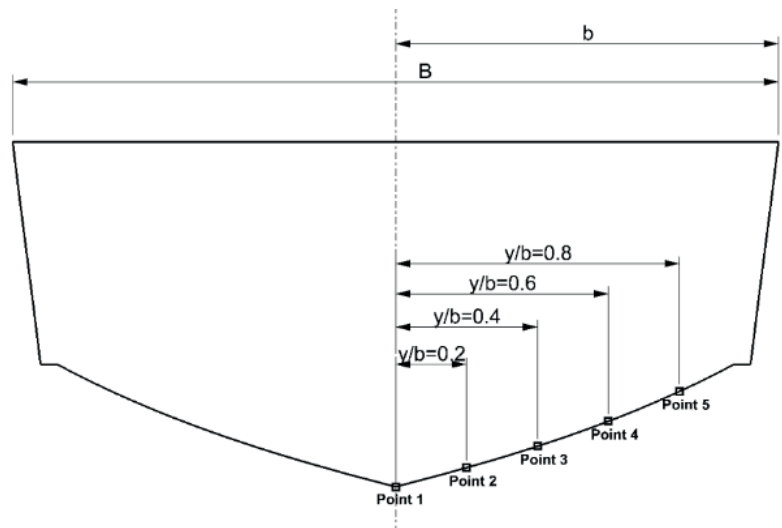

(b)

Fig. 13. (a) Longitudinal coordinate of sections and (b) positions of pressure calculation points (measures are in millimeters).

\section{Vertical acceleration}

The mean peak acceleration versus Froude number (Fn) are plotted in Fig. 14 for several sections. The term "mean peak" is defined as the average value of ten peaks from a single wave record. All sections show a rapid increase in the maximum peak acceleration as the Froude number increases. For the considered planing hull, a $46 \%$ increase of the Froude 
number results in about a $120 \%$ increase of the maximum peak acceleration. It is also observed that the acceleration increases from the aft sections to the fore sections. In the case of $\mathrm{Fn}=1.8$, a section at $\mathrm{x} / \mathrm{L}=0.3$ has the maximum peak acceleration of $20 \mathrm{~m} / \mathrm{s}^{2}$, while a section at $\mathrm{x} / \mathrm{L}=0.7$ has $50 \mathrm{~m} / \mathrm{s}^{2}$. As one may expect, both the parameters of the Froude number and the location of the section significantly affect the maximum peak acceleration.

The acceleration versus the distance from the transom is shown in Fig. 15 for different wave heights at the forward speed of $5 \mathrm{~m} / \mathrm{s}(\mathrm{Fn}=1.6)$. The maximum peak acceleration rapidly increases from aft to fore, for all wave heights similar to the Froude number. In addition, an increase in wave height significantly increases the maximum peak acceleration. The maximum peak acceleration of about $11 \mathrm{~m} / \mathrm{s}^{2}$ occurs at $\mathrm{x} / \mathrm{L}=0.7$ at a wave height of $\mathrm{H} / \mathrm{B}=0.111$, while it increases to $45 \mathrm{~m} / \mathrm{s}^{2}$ at $\mathrm{H} / \mathrm{B}=0.28$, more than four times.

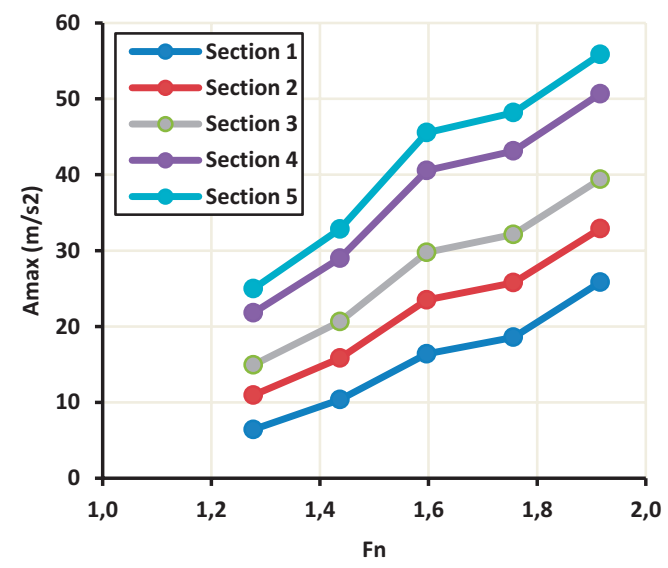

Fig. 14. Mean peak accelerations for different Froude number and positions at $H / b=0.28$

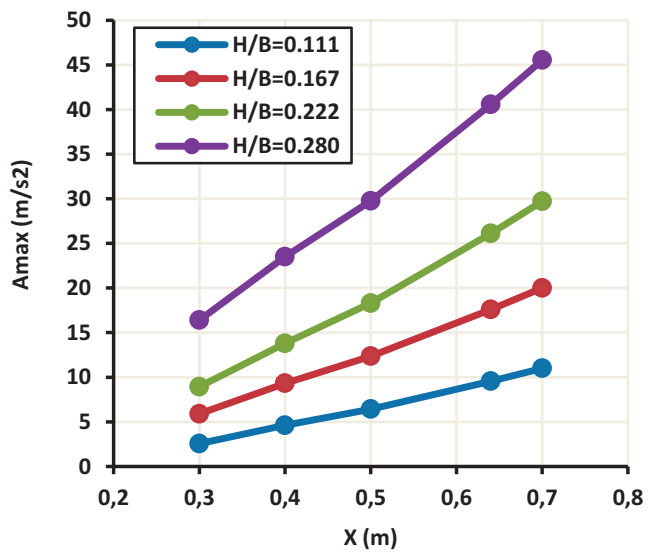

Fig. 15. Mean peak accelerations on craft sections for several wave heights at $V=5 \mathrm{~m} / \mathrm{s}$

\section{PRESSURE}

Three parameters, including local dead-rise angles, local vertical relative velocity and the chine-wet/chinedry condition, govern the maximum peak pressure. The dead-rise angle distribution is shown in Fig. 16. As can be seen, the dead-rise angle starts at the transom by 11 degrees and increases slowly to 20 degrees to $\mathrm{x} / \mathrm{L}=0.6$, then rapidly increases to 50 degrees at $\mathrm{x} / \mathrm{L}=0.9$ and remains at 50 degrees to $\mathrm{x} / \mathrm{L}=1.0$.

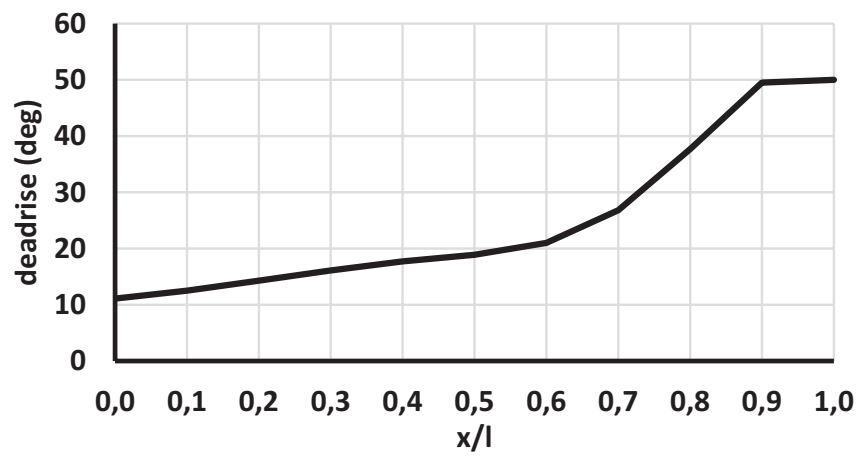

Fig. 16 Dead-rise angle distribution of the model.

On the other hand, the vertical relative velocity is typically higher far from the centre of gravity. Fig. 17 shows the peak of vertical relative velocity at different positions for a range of wave heights. The peak of vertical relative velocity increases with the increasing wave height and approaching the fore of the craft.

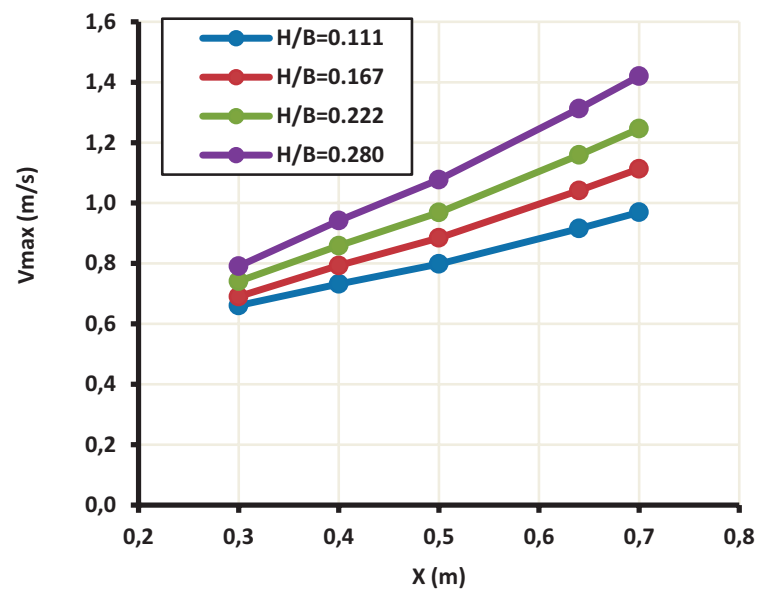

Fig. 17. Peak vertical relative velocity at different positions at $V=5 \mathrm{~m} / \mathrm{s}$

Overall, the pressure is a function of both the relative velocity and a dead-rise angle of more than a first-order. Therefore, the pressure at the fore part should increase due to a higher vertical relative velocity and should decrease due to a higher dead-rise angle, at the same time. The contradiction between the two effects may result in a non-monotonic pressure distribution. Additionally, the chine-wet condition drops the pressure to atmospheric pressure at the chine and significantly reduces the pressure in places near the chine. The sections located on aft to amid-ship frequently become chine-wet.

In Fig. 18, the maximum peak pressure of five sections at five points across each section $(y / b=0,0.2,0.4,0.6,0.8)$ for 
a range of wave heights are presented. Fig. 18 (a) demonstrates the maximum peak pressure on the keel-line as a function of the wave height along the keel length. The pressure along the craft's length is divided into two parts, the aft part from $\mathrm{x} / \mathrm{L}=0.3$ to the amid-ship and the fore part starting from the centre of gravity to $\mathrm{x} / \mathrm{L}=0.7$. At $\mathrm{H} / \mathrm{B}=0.111$, the pressure from the transom to the amid-ship increases, while from amid-ship to fore perpendicular it rapidly decreases. This trend changes as the wave height increases. For example, at a wave height of $\mathrm{H} / \mathrm{B}=0.28$, the pressure rapidly increases from $\mathrm{x} / \mathrm{L}=0.3$ to $\mathrm{x} / \mathrm{L}=0.65$ and continues with an almost constant value. Approximately the same trend can be seen in Fig. 18 (b), a point on the hull close to the keel line.

As the $y$-coordinate of the point under consideration increases, shown in Fig. 18 (a) to Fig. 18 (d), a tendency of pressure decrease is observed, especially for the fore part of the craft length. The aft part of the craft has almost the same pressure. Fig. $18(\mathrm{~d})$ and $(\mathrm{e})(\mathrm{y} / \mathrm{b}=0.6$ and 0.8$)$ show a tendency to yield the zero pressure for some sections located on $\mathrm{x} / \mathrm{L}=0.7$. The tendency to zero pressure is most likely related

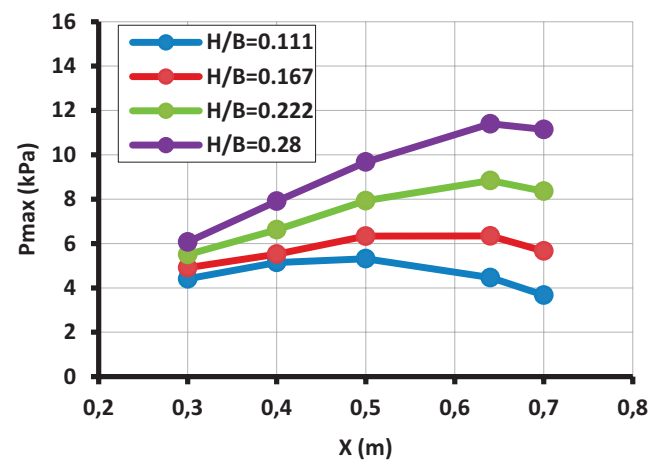

(a) $y / b=0$

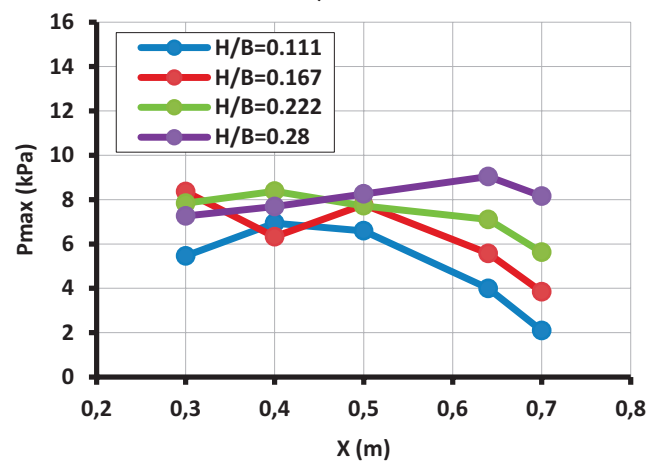

(c) $y / b=0.4$ to the unsubmerged condition of the sections at the fore. Furthermore, the maximum pressure curves have a fracture and decrease all at once ahead of $\mathrm{x} / \mathrm{l}=0.6$, as seen in Fig. 18 (a) to (e). This is because of the steep increase of the dead-rise angle in these sections.

An important engineering solution to keep the pressure and acceleration low in the fore part of the planing craft is to keep the dead-rise angle constant from transom to amid-ship, but with a rapid increase from amid-ship to the fore perpendicular. This study shows that this solution works effectively, and sometimes less pressure at the fore perpendicular is observed. It may be recommended to employ a kind of parametric study to find out the best geometry of the craft for the elimination of high-pressure especially in the fore of a craft.

Moreover, the results indicate that the combined method may be employed as a powerful tool to modify planing hulls design to achieve an even pressure distribution along the length of the planing craft.

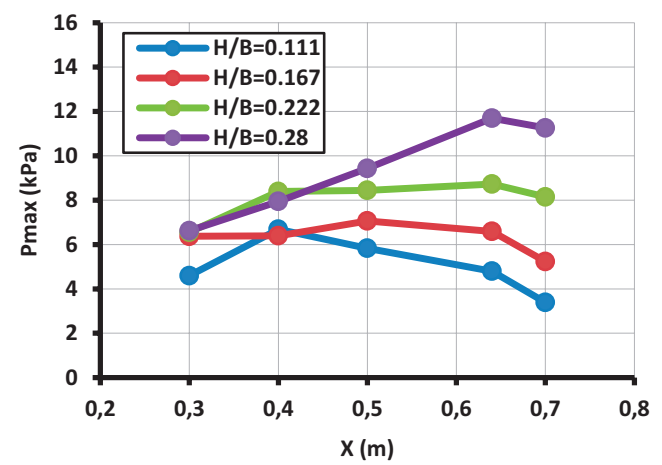

(b) $y / b=0.2$

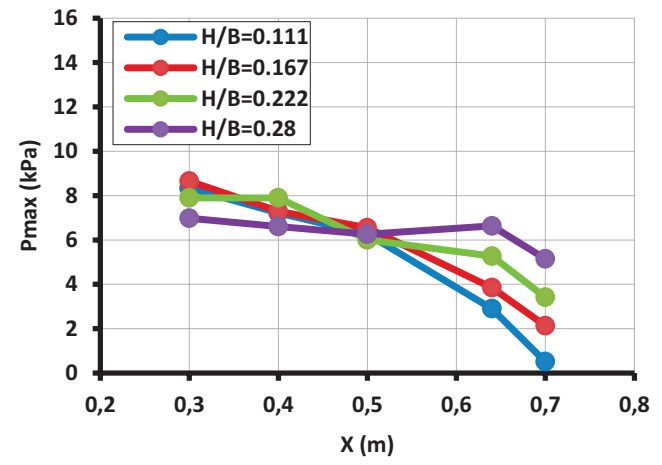

(d) $y / b=0.6$

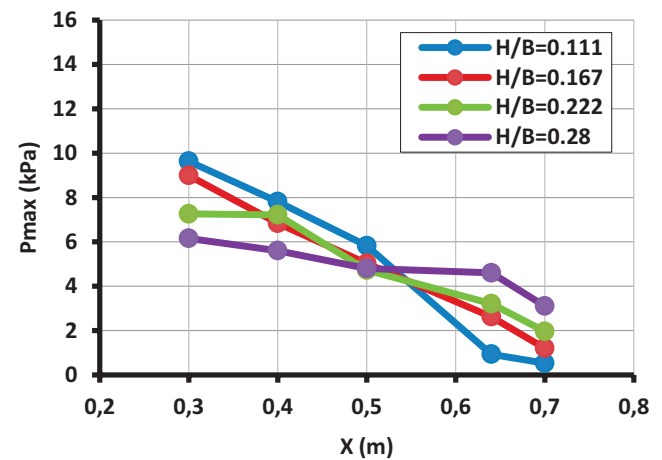

Fig. 18. Maximum pressure at a) $y / b=0, b) y / b=0.2, c) y / b=0.4, d) y / b=0.6$ and e) $y / b=0.8$ relative to the distance from the transom at $V=5 \mathrm{~m} / \mathrm{s}$. 


\section{CONCLUSIONS}

In this study, a computer code is developed based on combining the $2.5 \mathrm{D}$ method with the equivalent wedge method for calculation of the impact pressure on planing hulls in waves. The computer code also calculates heave and pitch motions as well as acceleration. A planing model was tested in calm water and regular waves with a wave height of $3.5 \mathrm{~cm}$ and wavelength of $300 \mathrm{~cm}$ at a speed of $6 \mathrm{~m} / \mathrm{s}$, and the recorded acceleration and pressure were compared with the results of the combined method. The calculated results in comparison with model experiment show a good agreement for heave and pitch motions, and acceleration. The pressure trend resulting from calculation is also in good agreement with the experiment, while the pressure peaks have relatively low agreement with the experiment. The combined method is utilised for a parametric study on acceleration and pressure for various velocities and wave heights. The parametric study reveals that the pressure and acceleration are evenly distributed along the craft, if the dead-rise angle is constant from transom to amid-ship, and gradually increases from amid-ship to the fore perpendicular. This study suggests that the optimum deadrise angle distribution along a planing craft should be extracted from an analysis similar to that presented in this paper.

\section{REFERENCES}

1. Fridsma G. (1969): A systematic study of the rough-water performance of planing boats. Stevens Inst of Tech, Hoboken, NJ, Davidson Lab.

2. Savitsky D., Brown P. W. (1976): Procedures for hydrodynamic evaluation of planing hulls in smooth and rough water. Marine Technology, 13(4), 381-400.

3. Martin M. (1976): Theoretical Prediction of Motions of HighSpeed Planing Boats in Waves. Journal of Ship Research, 22(3), 98

4. Zarnick E. E. (1978): A nonlinear mathematical model of motions of a planing boat in regular waves. David W Taylor Naval Ship Research and Development Center, Bethesda, MD.

5. Hicks J. D., Troesch A. W., Jiang C. (1995): Simulation and nonlinear dynamics analysis of planing hulls. Journal of Offshore Mechanics and Arctic Engineering, 17(1), 38-45.

6. Akers R. H. (1999): Dynamic analysis of planing hulls in the vertical plane. Proceedings of the Society of Naval Architects and Marine Engineers, New England Section.

7. Van Deyzen A. (2008): A nonlinear mathematical model of motions of a planing monohull in head seas. In Proceedings of the 6th International Conference on High Performance Marine Vehicles (HIPER'08).
8. Sayeed T. M. (2010): Numerical simulation of planing hull in regular waves. Memorial University of Newfoundland.

9. Ruscelli D. (2009): Dynamics of high-speed craft. $\mathrm{PhD}$ Thesis, University of Genoa, Genoa.

10. Pennino S. (2014): Vertical Motion Assessment for Planing Hulls. PhD Thesis, University of Naples Federico II, Naples, Italy.

11. Von Karman T. (1929): The impact on seaplane floats during landing. National Advisory Committee on Aeuronautics, Washington, DC.

12. Wagner H. (1932): Über Stoß-und Gleitvorgänge an der Oberfläche von Flüssigkeiten. ZAMM-Journal of Applied Mathematics and Mechanics/Zeitschrift für Angewandte Mathematik und Mechanik, 12(4), 193-215.

13. Howison S., Ockendon J., Wilson S. (1991): Incompressible water-entry problems at small deadrise angles. Journal of Fluid Mechanics, 222, 215-230.

14. Oliver J. M. (2002): Water entry and related problems. $\mathrm{PhD}$ Thesis, University of Oxford.

15. Smiley R. F. (1951): A Semiempirical Procedure for Computing the Water-Pressure Distribution on Flat and V-Bottom Prismatic Surfaces During Impact or Planing. National Advisory Committee for Aeronautics, Washington, DC.

16. Smiley R. F. (1952): Water-pressure distribution during landings of a prismatic model having an angle of dead rise of 22 1/2 degrees and beam-loading coefficients of 0.48 and 0.97. National Advisory Committee for Aeronautics, Washington, DC.

17. Gray H. P., Allen R. G., Jones R. R. (1972): Prediction of Three-Dimensional Pressure Distributions of V-Shaped Prismatic Wedges during Impact or Planing. David W Taylor Naval Ship Research and Development Center, Bethesda, MD.

18. Rosén A., Garme K. (2004): Model experiment addressing the impact pressure distribution on planing craft in waves. International Journal of Small Craft Technology, 146.

19. Rosén A. (2005): Impact pressure distribution reconstruction from discrete point measurements. International Shipbuilding Progress, 52(1), 91-107.

20. Camilleri J., Taunton D., Temarel P. (2018): Full-scale measurements of slamming loads and responses on high-speed planing craft in waves. Journal of Fluids and Structures, 81, 201-229. 
21. Razola M., Rosén A., Garme K. (2014): Allen and Jones revisited. Ocean Engineering, 89, 119-133.

22. Allen R. G., Jones R. R., Taylor D. W. (1978): A simplified method for determining structural design-limit pressures on high performance marine vehicles. In Advanced Marine Vehicles Conference.

23. Ghadimi P., Tavakoli S., Dashtimanesh A. (2016): Calm water performance of hard-chine vessels in semi-planing and planing regimes. Polish Maritime Research, 23(4), 23-45.

24. Ghassemi H., Kamarlouei M., Veysi S. T. G. (2015): A hydrodynamic methodology and CFD analysis for performance prediction of stepped planing hulls. Polish Maritime Research, 22(2), 23-31.

25. Jones R. R., Allen R. G. (1972): A Semiempirical Computerized Method for Predicting Three-Dimensional Hull-Water Impact Pressure Distributions and Forces on High-Performance Hulls. David W Taylor Naval Ship Research and Development Center, Bethesda, MD.

26. Shuford Jr C. L. (1958): A theoretical and experimental study of planing surfaces including effects of cross section and plan form. National Advisory Committee for Aeronautics, Washington, DC.

27. ITTC Member Organisations. Available from: https://ittc.info/members/member-organisations/ national-iranian-marine-laboratory-nimala/.

28. Yang S.-I., et al. (1996): The Prediction of Resistance of a $23 \mathrm{~m}$ Class Planing Hull. Journal of Hydrospace Technology, 2(2), 68-79.

29. Zeraatgar H., et al. (2019): Sampling rate effect on wedge pressure record in water entry by experiment. Ocean Engineering, 179, 51-58.

\section{CONTACT WITH THE AUTHORS}

\section{Hossein Tahmasvand}

e-mail: tahmasvand@aut.ac.ir Amirkabir University of Technology, Hafez, 15875-4413 Tehran,

IRAN

\section{Hamid Zeraatgar}

e-mail:hamidz@aut.ac.ir Amirkabir University of Technology, Hafez, 15875-4413 Tehran,

\section{IRAN}

